EPITAPH FOR THE THIRD MAN

Debra Nails

From the time of Aristotle, controversy surrounding the third man argument has been vast indeed. Each generation has its own group of philosophers/scholars who attempt anew to determine whether the argument is valid, and how its validity may have affected Plato's attitude toward the forms. Those concerned with the argument as presented in the Parmenides usually defend one of two particularly long-lived positions: (1) that , the argument is invalid, or (2) that Plato's recognition of the validity of the third man argument led to his dismissal of the theory of forms. I I hope to demonstrate that neither of these solutions to the problem of the relationship of the third man argument to Plato's philosopliy as a whole can prove satisfactory. Further, I shall show that the validity of the argument does not imply Plato's rejection of the theory of forms; Plato certainly does continue to hold such a theory. But first let us get before us the argument itself which I have divided into its three parts:

"I fancy your reason for believing that each idea is one is something like this: when there is a number of things which seem to you to be great, you may think, as you look at them ail., that there is one and the same idea in them, and hence you think the great is one."

"That is true," he said.

"But if with your mind's eye you regard the absolute great and these many great things in the same way, will not another great appear beyond, by which all these must appear to be great?"

"So it seems."

"That is, another idea of greatness will apnear, in addition to absolute greatness and the objects which partake of it; and another again in addition to these, by reason of which they are all great; and each of vour ideas will no longer be one, but their number will be infinite." 
"But, Parmenides," said Socrates, "each of these ideas may be only a thought, which can exist only in our minds; then each might be one, without being exposed to the consequences you have just mentioned."

"But," he said, "is each thought one, but. a thought of nothing?"

"That is impossible," he replied.

"But of something?"

"Yes."

"Of something that is, or that is not?"

"Of something that is."

"A thought of some single element which that thought thinks of as appertaining to all and as being one idea?"

"Yes."

"Then will not this single element, which is thought of as one and as always the same in all, be an idea?"

"That, again, seems inevitable."

"Well then," said Parmenides, "does not the necessity which compels you to say that all other things partake of ideas, oblige you also to believe either that everything is made of thoughts, and all things think, or that, being thoughts, they are without thought?"

"That is quite unreasonable, too," he said, "but Parmenides, I think the most likely view is, that these ideas exist in nature as patterns, and the other things resemble them and are imitations of them; their participation in $i d e a s$ is assimilation to them, that and nothing else."

"Then if anything," he said, "resembles the idea, can that idea avoid being like the thing which resembles it, in so far as the thing has been made to resemble it; or is there any possibility that the like be unlike its like?" 
"Ho, there is none."

"And must not necessarily the like partake of the same idea as its like?"

"It must."

"That by participation in which like things are made like, will be the absolute idea, will it not?"

"Certainly."

"Then it is impossible that anything be like the idea, or the idea like anything; for if they are alike, some further idea, in addition to the first, will always appear, and if that is like anything, still another, and a new idea will always be arising, if the idea is like that which partakes of it."

"Very true."

"Then it is not by likeness that other things partake of ideas; we must seek some other method of participation." 2

(Parmenides $132 a-33 a)$

I. The third man argument: valid or invalid? The most famous journal debate over the logical status of the third man argument began with vlastos ${ }^{3}$ and has not yet fully abated. A discussion of the major points on both sides of the dispute may help to make clear the kinds of assumptions which must be made on each side, whether one holds the third man argument to be valid or invalid. Vlastos call.s the third man argument "the record of honest perplexity," claiming that Plato did not have the skill at logic to recognize the invalidity of the argument, but could not prove it to be valid either. vlastos outlines the argument thusly:

(A1) If a number of things, a, b, c, are all F, there must be a single Form, F-ness, in virtue of which we apprehend $a, b, c$, as all $\mathbf{F}$.

(A2) If $a, b, c$, and F-ness are all F, there must be another Form, $F_{1}$-ness, in virtue of which we apprehend, a, b, c, and F-ness as all F.

He then works out what he believes to be two hidden assumptions, the Self-Predication Assumption, and the Honidentity Assumption: 
(A3) Any Form can be predicated of itself. Largeness is itself large. F-ness is itself $F$.

(A4) If anything has a certain character, it cannot be identical with the Form in virtue of which we apprehend that character. If $x$ is $F, x$ cannot be identical with F-ness.

But Vlastos goes on to prove that (A3) and (A4) are inconsistent. Since each is necessary and they ar'e together sufficient for deriving (A2) from (AI), the third man argument is invalid.

Sellars, 5 certain that Plato was convinced by the third man argument, reformulates the argument as a lengthy proof so that it is consistent, but stops short of claiming that Plato was aware of all the steps necessary to make the argument consistent: Premises: $(G)=$ If a number of entities are all $F$, there must be an $\mathrm{F}$-ness by virtue of which they are all $\mathrm{F} ;(\mathrm{SP})=\mathrm{All}$ $F$-nessess are $F ;(N I)=$ If $x$ is $F$, then $x$ is not identical with the "F-ness by virtue of which it is $F$; $(P)=$ $a, b, c$, etc., particulars, are F.

(1), (P)

(1) = If $a, b, c$, etc., are $F$, there is an F-ness by virtue of which they are $\mathrm{F}$.
(2), (3), (SP) (4) F-ness 1 is F.
(4), (P)
(5) a, b, c, etc., and $\mathrm{F}_{\text {-ness }}$ are all $\mathrm{F}$.
(G)
(6) $=$ If $a, b, c$, etc., and F-ness 1 are all $F$, then there is an $F$-ness by virtue of which they are all F.

(7) There is an F-ness by virtue of which $a, b, c$, etc., and $F$-ness 1 are all F.

(8) Call this F-ness, "F-ness 2 ."

(NI)

(9) If $F$-ness 1 is $F$, then $F$-ness 1 is not identical. with F-ness by virtue of which it is $F$.

(4), (8), (9) (10) F-ness 1 is not identical with F-ness 2 .

(G) (11) $=$ If a, b, c, etc., and $\Gamma$-ness $]$ and $\mathrm{F}$-ness 2 are all $\mathrm{F}$, then there is an F-ness by virtue of which they are all F. 
(13) a, b, c, etc., and F-ness 1 and $\mathrm{F}$-ness 2 are all $\mathrm{F}$. - . ad libitum.

Vlastos, needless to say, is unconvinced by Sellars.

Geach $^{6}$ is next to enter the debate; he is primarily in agreement with Vlastos (that Plato was perplexed by the argunent), but is certain that Plato would have realized the inconsistency that Vlastos has pointed out. Therefore Geach looks for a more subtle inconsistency. He examines Plato's use of abstract nouns as a means to discovering the implicit assumptions of the third man argument which Plato would not have recognized:

(1) There is a set consisting just of the many fs that are not Forms.

(2) If $x$ is a Form by which $y$ is made to be an $F$, then $y$ is not a Form by which $x$ is made to be an $F$.

(3) If $A$ is a set of several Fs, and $x$ is an $F$ not belonging to $A$, then there is a set of Fs containing just the members of $A$ together with $x$.

(11a) Some F is a Form by which all other Fs are made to be Fs.

(4b) Any set consisting of several Fs are all of them made to be Fs by a form that is itself an F.

The original debate ends with Vlastos' final rebuttal to Geach; but the controversy itself continues to resemble Plato's early (Socratic) dialogues in being inconclusive.

Strang, ${ }^{7}$ following Vlastos, imagines that Plato's thought goes through various changes which admit various doctrines. Unlike vlastos, however, Strang constructs what he believes to be a consistent rendering of the third man argument (the numbers refer to clauses in the first section of the third man argument):

1. Let there be several (a set of) A's; call them Set 1 .

OII Given a set of A's, they participate in one and the same $F(A)$.

2. By $O M$, the $A^{\prime}$ 's of Set 1 participate in one and the same $F(A)$; call it $F_{1}(A)$. 
3. There is one and only one $F(A)$. ('The Uniqueness Thesis, $U$ for short).

SP $\quad F_{1}(A)$ is an $A$.

NI $\quad F_{1}(A)$ is not a member of set 1 .

4. By SP and NI, the $A^{\prime}$ s of set 1 together with $F_{1}(A)$ form a new set of $A^{\prime}$ s; call it Set 2 .

5. By $O M$, the $A^{\prime}$ s of Set 2 participate in one and the same $F(A)$; call it $F_{2}(A)$.

SP $\quad F_{2}(A)$ is an $A$.

NI $\quad F_{2}(A)$ is not a nember of set 2 .

6. By $N I, F_{2}(A)$ is another $F(A)$ [i.e., it is not identical with $\left.F_{1}(A)\right]$.

7. Moves 4-6 may be repeated again, and indeed indefinitely.

8. Therefore there are an infinite number of $F(A)$ 's .

9. Therefore not-IJ.

What is interesting is that strang is not only willing to allow that the third man argument rests on both the Self-Predication Assumption and the Non-Identity Assumption, but claiuns that Plato also recognized these presuppositions. Strang blames vlastos for formulating the Non-Identity Assumption in such a way that it would appear inconsistent with the Self-Predication Assumption. As a result of his analysis, strang asserts that Plato consigns to the grave--not the third man-but the theory of forms.

Teloh and Louzecky, 8 more recent contributors to the debate, also find the third man argument to be consistent; their evidence is primarily textual. vlastos, according to these authors, is guilty of reading peculiar translations from the freek text. 9 Their examples are abundant; and $I$ believe their case to be compelling. A major presupposition of the position of Teloh and Louzecky (which deviates from the tradition of the third man argument) is, however, that the second step of the argument is not derived from the first. Again, their evidence for so construing the argument is textual. In their view, the steps of the argument are properly interpreted as narallel. There is no "logical gap" between the first step and the second because, although it is appropriate to apply the 
same reasoning at each step, "this reasoning is employed about different sets." They further posit a general statement which they believe capable of generating all the steps of the arguinent:

(T) If a number of things are $F$, there is a single Form in virtue of which we apprehend these things as $F$, and these things (either individually or in any combination) are not identical with this Form.

I am convinced that some rendering of the third man argument as valid--with both Strang and Teloh/ Louzecky providing likely accounts--is necessary. A pressing problem for those who believe that Plato held the third man argument to be invalid is to account for the fact that plato nowhere in his writings takes on the third man and defeats him. If Aristotle is to be trusted, Plato did not do so in his Academic lectures either. The evidence, in fact, points to the contrary: compare Sophist $217 \mathrm{c}$ where Socrates (in conversation with the Eleatic Stranger) gives credit to Parmenides for having made magnificent arguments to Socrates one day when Socrates was young. Ravenlo strikes a middle position. He describes the purpose of the third man argument of the Parmenides as to affect a dialectical movement. Although he goes on to posit (wrongly, I believe) that the argument is invalid, his major point is still an excellent one. Raven accuses Parmenides of making a materialistic interpretation of the forms. In the first moment of the dialectic, "greatness" is just another large thing (the view which Aristotle later presents). The second moment, wherin the forms are represented as thoughts, allows Plato to dispose critically of a possible inisinterpretation of the theory of forms. Finaliy, the thesis that the forms are "patterns" serves as a dialectical conclusion. After all, is this view of the forms-as-patterns not similar to that presented in the Timaeus? Unfortunately, as Parmenides points out, the third man certainly does emerge to strike at the third moment. Raven claims here that an "obvious" fallacy is committed: the thing does not just resemble the pattern; it is derived from the pattern. Yethe takes the passage to be a successful criticism of the theory of forms as presented in the Phaedo, unsuccessfu? against the more elaborated theory of the Republic. 11

II. Plato's judgment: valid. But did Plato himself hold that the third man argument was valid? A chief argument that he did not is reiterated by Raven, ". . Whatever objective validity any of Parmenides' 
criticisms may possess, Plato himself, who either invented them or borrowed them from his critics, sonehow managed to remain undismayed" ( $p .217$ ). Others have shared this view, that Plato's acknowledgment of "forms" in dialogues certainly later than the Parnenides ( $\mathrm{e} . \mathrm{g}$. Sophist and ('imaeus) serves as textual evidence that Plato was unswayed by the third man argument.12 But to counter this, let me present two relevant bits of Platonic evidence:

"Now God, whether because he so willed or because some compulsion was laid upon him not to make more than one couch in nature, so wrought and created one only, the couch which really and in itself is. But two or more couches were never created by God and never will come into being."

"How so?" he said.

"Because," said I, "if he should make only two, there would again appear one of which they both would possess the form or idea, and that would be the couch that really is in and of itself, and not the other two." (Republic 597c) 13

Are we right, then, in describing the Heaven as one, or would it be more correct to speak of heavens as many or infirite in number? One it must be termed, if it is to be framed after its Pattern. For that which embraces all intelligible Living Creatures could never be second, with another beside it; for if so, there must needs exist yet another hiving Creature, which should embrace them both, and of which they two would each be a part; in which case this Universe could no longer be rightly described as modelled on these two, but rather on that third creature which contains them both. (Timaeus 31 a)

According to Cherniss, 15 Plato's casual use of this argument (as in the above examples) demonstrates that Plato was unafraid of the third man argument, believing it to be irrelevant.16 The third man argument applies, says Cherniss, only if idea and particular be treated as homogeneous members of a multiplicity. This provides no solution, for the question of whether the "resemblance" between idea and particular allows us to count the ideas with the particulars in some larger conlext (making them, in a sense, part of the same "multiplicity") is exactly what is at issue here. No, I tlink Plato mentions the objection to the theory of forms regularly as a sort of reminder to the reader that the theory-as- 
presented is in fact subject to such objections. 17 What I am suggesting is perhaps less incredible than it may at first sound; I shall attempt to build the case that Plato recognized that any articulated version of his theory of forms would inevitably be lacking, would inevitably fall to the third man, and that Plato nonetheless held a "theory of forms," as Aristotle claims he did. 18

III. Plato's theory of forms after the third man argument. Let me first recant the title of this section, for $\bar{I}$ take it that neither the theory of forms (as represented in Parmenides) nor the third man argument were original with Plato.19 Several dramatic devices employed by Plato in the Parmenides contribute to this assumption: $(A)$ Socrates is presented as a very young man, untutored in the method of dialectic; the theory he presents is an elementary one (so elementary, in fact, that Socrates denies there to be forms of sucli natural substances as hair and dirt). (B) Parmenides asks the young Socrates directly, ". . . did you invent this distinction yourself, which separates the abstract ideas from the things which partake of them?" (130b) Yet the old man does not wait for an answer; instead he imnediately asks another question. Socrates responds only to the second. We see, then, that the first question was intended rhetorically. This becomes even more evident when (C) Parmenides reintroduces the forms $(135 b-c)$ in a way which indicates that this is no "new" theory to hiin.

Historically as well, we have good reason to believe that some kind of "theory of forms" predates Plato. Aristotle suggests such in the Metaphysics $(987 \mathrm{~b} 4-11)$ :

Plato accepted his (Socrates') teaching, but held that the problem applied not to sensible things but to entities of another kind--for this reason, that the common definition could not be a definition of any sensible thing, as they were always changing. Things of this other sort, then, he called Ideas, and sensible things, he said, were all named after these, and in virtue of a relation to these; for the many existed by participation in the Ideas that have the same name as they. Only the natne 'participation' was new. 20

This passage, although it suggests only that the notion of forms was at least as old as Socrates, is straightforward in $i$ ts assertion that neither sensible things nor forms were new concepts with Plato; only "participation" was novel. 
If both the forms and the third man argument do predate Plato, what have we shown? At least this: that Plato inherited the clear criticisins of the theory of forms along with the theory itself. So the first kind of formulation of the theory of forms--which we might think of as the first moment in the long dialectic attached to the theory--is exactly that kind which we find in the Parmenides. Importantly, the Parmenides, far from being the end of the theory of forms, is--in terms of sophistication--the very beginning of the articulation of that theory; it provides a most elementary formulation.

Lest the reader despair at my claim that Plato could write a "middle dialogue," the Parmenides, with an unsophisticated "early" theory represented there, let us step aside for a moment and look at the whole Platonic endeavor. Since I am assuming a "context" for the dialogues, I should perhaps share this with the reader. Whatever the limitations of the written word, and whatever the commitment to the superiority of dialectic, Plato must have believed that written dialogues could provide meaningful assistance to those at the Academy who were at various level.s in their philosophic development. Because the more advanced students were able to profit from more sophisticated material than beginners, Plato composed dialogues of different degrees of complexity, much as a set of textbooks inight be compiled. If we look at Plato's writing in this way, we will find ourselves opposed to the long tradition of scholars who see Plato as "developing" (and perhaps later abandoning) a theory. Instead--and this is how I shall argue in what follows--Plato may be understood as holding a sophisticated theory of forms which he articulates to a greater or lesser degree, depending on the focus and subject matter of each dialogue.

I have already indicated that the ontological theory of the Parmenides is an elementary one. Now we must turn to successively more developed treatments of the theory of forms in the dialogues. Through (however brief) accounts of the Phaedo, the Repubiic and the Sophist, we will trace accounts of the forms and suggest how each is affected by the valid third man argument.

The Phaedo provides a statement of the theory of forms which--as in the Parmenides--is subject to the third man. I mention it here because it is so frequently cited for the theory and because it represents a theory at least somewhat more developed than that of the Parmenides. The rich words of Socrates insist on the intuition that something like the theory of forms is correct, but make no claims about truth: "I hold simply and plainly and perhaps foolishly to this, that nothing 
else makes it beautiful but the presence or communion (call it which you please) of absolute beauty, however it may have been gained; about the way in which it happens, I make no positive statement as yet, but I do insist that beautiful things are made beautiful by beauty" (100d).21

By this account, absolute beauty, as the perfect instance of itself, is another beautiful entity "alongside" beautiful things; this necessitates the positing of a third "Beauty" in terins of which both the beautiful things and absolute beauty are beautiful. But this is, of course, precisely what the third man is about.

A still more sophisticated version of the theory of forms--but one yet arguably victim to the third man-is the theory we find represented in Book VI of the Republic, the account of the divided line. The third and fourth levels of the line are relevant here since only these admit forms. The third is the locus for an elementary type of forms: mathematical and geometric truths (the seginent is the same length as the second [physical objects] because we can exhaustively describe any physical object in terms of its mathematical predicates--when "mathematical" is construed broadly to include physical laws). I take it that the third man argument, if applied to this sort of form, would go something like this: there is some third thing by virtue of which both the triangle and triangularity are triangular. Now I admit it seems rather odd to put the argument this way; and it is still more odd to imagine what sort of similar argument would have to be used in the case of arithmetic. There is some third thing by virtue of which both " $2+2=4$ " and " 2 apples +2 oranges $=4$ pieces of fruit" are alike.

Yet the third level is not fundamental for Plato (and thus, is of less concern to us) since mathematics relies on unproven definitions and axioms. The fourth level is posited as the "ground" of the third, each level of the line having been shown to be dependent on the level above it. Now, the content of the fourth level (which we come to understand dialectically) is represented as the most fundamental level of the line itself, free of any hypotheses, the level of Platonic forms. Finally, there is the food which stands beyond the whole scheme and is the cause of it all.22 clearly, the third man argument could be applied to the fourth level themselves (in exactly the same way as the Phaedo's analysis of beauty was described above) but I suggest that r'lato here provides his own third man, the Good. What I mean is that, insofar as the Good is the cause of a beautiful thing's participation in the form 
of beauty, it is itself "that in virtue of which both the beautiful thing and beauty are beautiful." But this is of little consolation since, as the arpument runs, we should now ask for that in virtue of which the beautiful thing and beauty and the food are all alike. No, we do not yet have an invulnerable version of the theory. (Yet, surely, the reader begins to feel a sort of slippage in the fit of the argument to the subject matter.)

What I believe to be the most sophisticated view of the theory of forms appears in the Sophist. Being is represented as ontologically fundamental; inotion, rest, sameness, and difference correspond to what--in the Republic--were fourth level forms. It is easy to see how we might apply the third man argument here (in precisely the way it was applied to the trio of the Good, beauty, and the beautiful thing). I do not wish to deny that the argument could be so used. llowever, what I want to suggest is that at least in the case of the Sophist (but, likely, in the case of the Republic as well) the third man argument seems inappropriate, even irrelevant.

There is in the Sophist a more complex system of forms to be elaborated. Whereas--in all the other Platonic accounts of the theory of forms--there is an explicit order, a progression through "levels of being" where each succeeding level is distinct and more ontologically fundamental than its preceding level (and it is not entirely misleading to think of these levels as expressing various degrees of abstraction), the Sophist cannot be so described. Motion is not a more abstract version of some particular moving thing, at least not in the way that beauty seems a more abstract description of some beautiful particular thing. The unique nature of the ontology of the Sophist is in the relations among the forms (or kinds, yévn) themselves. All particular things must participate in some combination of motion, rest, sameness, difference, and in being. But, although we might advance the argument of the third man, it would sound even more curious than we noted in the case of the Republic. It would go, "there must be some fourth thing by virtue of which being, motion, and the loping gazejle are all alike." One wants to complain that, although we understand what is meant by the argument, it seems to miss the point. Being is not itself some third discreet thing in terns of which we describe both motion and the loping gazelle, nor is motion to be included alongside other particular moving entities with a claim that might go, "motion itself moves." Or so I maintain. 
But let us say that we do hold the third man argument to be relevant here, that we are untroubled by such inelegant expressions. Still, we are left with Plato's own apparent continuation in holding the theory of forms. Ilow are we to account for this? A rather standard disclaimer may be appropriate here: we are mistaken if we expect to locate the kennel of Plato's theory of forms in the dialogues themselves. As he says in Epistle VII (34lc-d):

There does not exist, nor will there ever exist, any treatise of mine dealing therewith (the subjects which I seriously study). For it does not at all admit of verbal expression like other studies, but, as a result of continued application to the subject itself and communion therewith, it is brought to birth in the soul on a sudden, as light that is kindled by a leaping spark, and thereafter it nourishes
itself. 23

Similarly, the Phaedrus criticizes the written word: ". . . no written discourse, whether in metre or in prose, deserves to be treated very seriously."2" The dialogues are propaedeutic to the most sophisticated aspects of Plato's philosophy.25 Another dialectical movement must be made to a theory still more fundamental.

Now if Plato's philosophy cannot be written, then certainly I an not about to reveal the "true theory of forms": but undoubtedly it is not enough for one to claim simply that there is a more fundamental theory and leave it at that. Plato provides a glance at the means to move beyond the earlier versions of the theory in Republic VII, in his discussion of the education of the guardians. As llavelock argues (against Cherniss and the whole scholarly history of the Academic curriculum), Plato woul.d not have restricted study to plane and solid geometry and the number theory (discreet sciences of the day). It has been held that, since the sciences of icleal astronomy and ideal hamonics "did not exist," Plato could not have taught them. But Havelock points out that the business of the Academy must have been the creation of such sciences, for Plato explicitly recognizes these in the Republic. Although Speusippus may have rejected the theory of forms, although Xenocrates may have converted the forms into mathematical numbers, it was still the case that the business of philosophy in the Acaclemy was the "process of isolation and abstraction." The most fundamental description of what is cannot be articulated, can only be identified by pointing. 26 l'le purpose, then, of the instruction was, 
"to introduce the pupil . . . to problems or propositions concerning moving bodies and musical harmonies out of which he would be constrained, for example, to grasp motion as a purely abstract conception, expressing a genus which exists in two different species, and to contemplate the necessity of composing analytic formulae or 'definitions' which translate particular motions in terms of general laws." 27 Certainly number theory was not (is not) the most fundamental truth, yet even this was beyond what Plato could offer in his propaedeutic dialogues. It was possible to study astronomy (as the science of solid bodies in motion) in the Academy, but set theory and theoretical mathematics which might provide a ground for theoretical physics and astronomy, were almost certainly still out of reach. 28

The theory of forms, in any articulated version, made that which is most abstract less abstract than it is (i.e., concrete enough to be written or spoken of). So no matter how far away from the early versions of the theory of forms (his own or others') Plato moved dialectically, the non-demonstrable aspects were still out of reach, much as Parmenides points out at $135 \mathrm{~b}-\mathrm{c}$.

\section{University of Kansas}




\section{NOTES}

$l_{\text {llere I wish to oppose only a particularly strong }}$ form of the position: that Plato--after having written a number of dialogues, and after having posited the theory of forms--developed (or, perhaps, had brought to his attention) the argument which has come to be called "the third man"; further, that Plato recognized this argument as fatal to the theory of forms and therefore rejected that theory.

2H. H. Fowler, translator.

${ }^{3}$ Gregory Vlastos, "The Third Man Argument in the Parmenides," Philosophical Review, LXIII (1954), Pp. $319-49$.

"Vlastos also states that the recognition of the hidden premises of the third man argument and their "intolerable" logical consequences would have been fatal to Plato's Separation Theory and Degrees-of-Reality Theory: "lle was thus holding consciously a metaphysical Theory whose disastrous implications were hidden from his conscious mind" ( $p .343$ ).

"Wilfrid Sellars, "vlastos and the Third Man," Philosophical Review, LXIV (1955), pp. 405-37.

${ }^{6}$ Peter Geach, "The Third Man Again," Philosophical Review, L.XV (1956), pp. 72-82.

${ }^{7}$ Colin Strang, "Plato and the Third Man," Proceedings of the Aristotelian Society, Supplementary Vol. No. $37(\overline{1963), ~ p p . ~ 147-61 . ~}$

8 llenry Teloh and David James Louzecky, "Plato's Third Man Argument," Phronesis, XVII (1972), pp. 80-94.

${ }^{9}$ In particular, Teloh and Louzecky reject Vlastos'

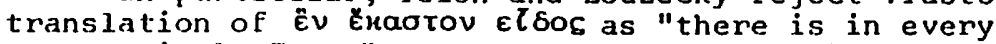
case a single Form." They suggest instead, "in every case the Form is one."

$10 \mathrm{~J}$. F. Raven, Plato's Thought in the Making (Cambridge: Cambridge University Press, 1965), pp. 213-24. 
$11_{\text {There are literally dozens of articles which }}$ continue the controversy, but the "sides" of the dispute have been adequately represented here, I believe.

12 Needless to say, this view presupposes that a "progression" can be traced from the early to the late dialogues--a view at best controversial.

${ }^{13}$ Paul Shorey, translator.

${ }^{14}$ R. G. Burry, transaltor.

15 Harold F. Cherniss, Aristotle's Criticism of Plato and the Academy (Baltimore: The Johns Hopkins Press, $\overline{1944), ~ p p . ~ 293-98 . ~}$

${ }^{16}$ Cherniss' implication that Plato would not have mentioned arguments which he believed to be destructive of his own theories in curious, of course, to anyone who takes the dialectical method seriously.

17 An interesting similar case is that Parmenides' "sail" objection to the theory of forms occurs at Euthydemus 300e-30la [Rosamond Kent Sprague, "Parmenides' Sail and Dionysodorus' 0x," Phronesis, XII (1967), pp. 91-98], and at Philebus 15b-c.

18 At Metaphysics 987 a35, Aristotle speaks of Plato's having held "even in later years" (presumably while Aristotle studied with Plato at the Academy) that there is no knowledge of the "sensible things" which Aristotle goes on to contrast with the "ideas."

Aristotle remains an enigma. As the first postPlatonic thinker to discuss the third man argument, we turn to him. But his account is fraught with problems which have plagued scholars for two millennia. I shall attempt to answer a few of the questions which present themselves (in line with my analysis of Plato's view). The relevant textual references are Metaphysics 987 a29ff., $1.038 \mathrm{~b} 34 \mathrm{ff} .$, and On Sophistical Refutations 178b $37 \mathrm{ff}$. An excellent treatment of the lost essay $\pi e p i$ i $6 E \tilde{\omega} v$ is $G$. E. L. Owen, "A Proof in the IIEPI I Hellenic Studies, LXXVII (1957), pp. 103-11.

$Q$ : Why does Aristotle not credit Plato with having considered the third man argument in the Parmenides? A: The third man argument--like the theory of forms in its elementary version--was not original with Plato. Both probably were rather common positions among philosophers. Q: If Plato dismissed the third man argument in Academic discussion (rather than in the dialogues) why did Aristotle not mention Plato's criticism? 
A: Plato does not "dismiss" the third man argument because it is valid for the articulated versions of the idea theory. Q: Why does Aristotle assign to Plato so elementary a theory of forms, if Plato's Academic teaching suggested that the "real" theory of forms could not be written? A: Aristotle's account of Plato's theory of forms occurs in the midst of what appears to have been a lecture of the most general nature, tracing the history of philosophy until his own time. Elsewhere, he refers to "friends of the forms," not to Plato.

${ }^{19}$ Cherniss has argued, convincingly I believe, that the third man argument could not have been original with Plato or Aristotle (Cherniss, pp. 292-93), discounting the popular but fanciful theory that Aristotle--soon after his arrival at the Academy--introduced Plato to the third man, whereupon Plato wrote the Parmenides and dismissed the theory of forms. More interesting, perhaps, is the work of Eric A. Havelock ["The Origin of the Forms," Preface to Plato (New York: Grosset and

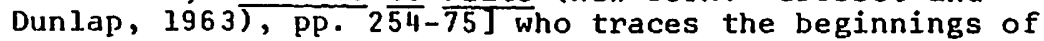
the theory of forms back to Empedocles and (with less certainty) to the atomists.

20 W. D. Ross, translator. When Ross translates

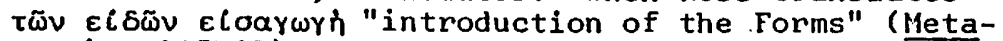
physics 987b31), he renders the phrase in the middle voice; it should properly be tanslated to reflect the active voice: "importation of the Forms."

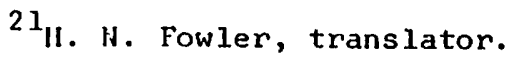

22 An interesting similar account is found in the Philebus ( $23 c-d, 66 a-c)$, where "the god" or "eternal nature" is said to be the cause of the ordering of such (fourth level) forms as measure, the measured, finite, and infinite.

${ }^{23}$ R. G. Bury, translator.

2"H. N.'Fowler, translator.

${ }^{25}$ CF. Parmenides $135 \mathrm{~b}-\mathrm{c}$. Parmenides' reintroduction of the forms implied the necessity of non-demonstrable principles of knowledge, if any knowledge be possible.

${ }^{26}$ Similar is the theology of Paul Tillich who, following certain medieval philosophers, makes the case for religious symbols" "showing the way" to Gocl--or man's ultimate concern--although God qua God cannot be articulated. 
27 liavelock, pp. 273-74.

${ }^{28}$ I am indebted to Professor Richard Cole for dragging me out of the cave on these points. 